\title{
The Interplay Between Post-Critical Beliefs and Anxiety: An Exploratory Study in a Polish Sample
}

\author{
Jacek Śliwak • Beata Zarzycka
}

Published online: 18 June 2010

(C) The Author(s) 2010. This article is published with open access at Springerlink.com

\begin{abstract}
The present research investigates the relationship between anxiety and the religiosity dimensions that Wulff (Psychology of religion: classic and contemporary views, Wiley, New York, 1991; Psychology of religion. Classic and contemporary views, Wiley, New York, 1997; Psychologia religii. Klasyczna i wspołczesna, Wydawnictwo Szkolne i Pedagogiczne, Warszawa, 1999) described as Exclusion vs. Inclusion of Transcendence and Literal vs. Symbolic. The researchers used the Post-Critical Belief scale (Hutsebaut in J Empir Theol 9(2):48-66, 1996; J Empir Theol 10(1):39-54, 1997) to measure Wulff's religiosity dimensions and the IPAT scale (Krug et al. 1967) to measure anxiety. Results from an adult sample $(N=83)$ suggest that three dimensions show significant relations with anxiety. Orthodoxy correlated negatively with suspiciousness (L) and positively with guilt proneness (O) factor-in the whole sample. Among women, Historical Relativism negatively correlated with suspiciousness (L), lack of integration (Q3), general anxiety and covert anxiety. Among men, Historical Relativism positively correlated with tension (Q4) and emotional instability (C), general anxiety, covert anxiety and overt anxiety. External Critique was correlated with suspiciousness (L) by men.
\end{abstract}

Keywords Post-Critical Belief · Religion · Religiosity · Religious belief · Anxiety

\section{Introduction}

The aim of the present study was to explore whether the way in which people approach religion is related to anxiety and if so, how these two notions are related to each other.

\footnotetext{
J. Śliwak · B. Zarzycka ( $₫)$

Department of Social Psychology and Psychology of Religion, Institute of Psychology,

The John Paul II Catholic University of Lublin, Al. Racławickie 14, 20-950 Lublin, Poland e-mail: zarzycka@kul.lublin.pl

J. Śliwak

e-mail: sliwak@kul.lublin.pl
} 
The relationship between religiosity and anxiety is a relatively common topic in the literature of the psychology of religion-in particular, regarding the function of religiosity in personality (Shreve-Neiger and Edelstein 2004). In the existing overview of the empirical research pertaining to the relationship between religiosity and psychic health (Gartner et al. 1991) and between religiosity and anxiety (Shreve-Neiger and Edelstein 2004), we paid special attention to the inconsistency of the results that various researchers obtained (Loewenthal 2006). Some studies provide evidence for the supposition that there is no correlation between religiosity and anxiety (Fehr and Heintzelman 1977; Frenz and Carey 1989; Francis and Jackson 2003; Huntley and Peeters 2005). Other studies show that there are significant correlations. Researchers observed a positive correlation between anxiety and external religiosity and a negative correlation between anxiety and internal religiosity (Sturgeon and Hamley 1979; Baker and Gorsuch 1982; Bergin et al. 1987; Davis et al. 2003). They also confirmed a negative correlation between anxiety and the ability to express religious needs (Maltby 1998) and a positive correlation with religious crisis (Pfeifer and Waelty 1999). Wilson and Miller (1968) found that individuals who undertake religious practices are characterized by a higher level of anxiety. Gupta (1983) showed that a higher level of anxiety characterizes individuals with high orthodox religiosity. Śliwak (2006) confirmed correlations of anxiety with the types of relation to God measured with the Hutsebaut (1980) scale of Relationship to God: Anxiety correlated positively with rebelliousness toward God and with guilt and negatively with identification with Christ and co-humaneness. Prężyna (1969) confirmed a negative correlation of the intensity of religious attitude with anxiety among men. Moreover, an interesting trend of studies on religiosity and fear of death has emerged. In this respect, the results also turned out to be diverse. For instance, Rasmussen and Johnson (1994) confirmed that fear of death is not related to religiosity, but Westman and Brackney (1990) found negative correlations between fear of death and religiosity (see also Roff et al. 2002; Śliwak 2005).

In their critical review of the literature regarding correlations between religiosity and anxiety, Shreve-Neiger and Edelstein (2004) suggested that defining both variables as uniform constructs may be the reason for discrepancies observed in study results. They recommended applying definitions that would encompass particular dimensions of religiosity and typological and structural elements of anxiety (see also Baker and Gorsuch 1982; Harris et al. 2002).

Following this recommendation, we decided to rely on the theoretical framework of Wulff $(1991,1997)$ and investigated the relationship between anxiety and Wulff's ((1991, 1997)) approach to religion. First, we will summarize Wulff's theory and introduce the Post-Critical Belief scale.

David Wulff $(1991,1997,1999)$ suggested a new and interesting perspective on religion in a secularized socio-cultural context. In the epilogue of his influential book, Wulff (1991, $1997,1999)$ argued that the various possible approaches to religion can be positioned in a two-dimensional space (see Fig. 1). The vertical axis in this space specifies the degree to which the objects of religious interest are granted participation in a transcendent reality (Exclusion vs. Inclusion of Transcendence). The horizontal axis indicates whether religion is interpreted literally or symbolically (Literal vs. Symbolic). Hence, these two dimensions define four quadrants, each reflecting a potential approach to religion: Literal Affirmation, Literal Disaffirmation, Reductive Interpretation and Restorative Interpretation (see Fig. 1; Hutsebaut 1996).

The upper left quadrant, Literal Affirmation, represents a position most clearly embodied by religious fundamentalism. However, elements of this posture also appear among individuals who are not particularly conservative. According to Wulff $(1991,1997$, 
Fig. 1 Integration of the three Post-Critical Belief subscales in Wulff's (1991, 1997, 1999) theoretical model according to Hutsebaut (1996) (see Fontaine et al. 2003)

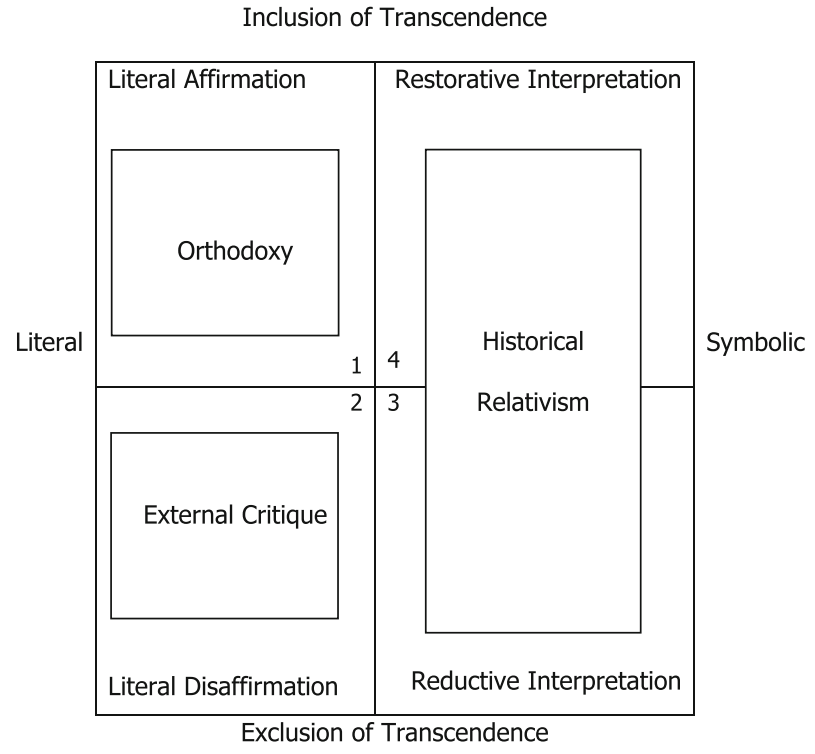

1999), this position, which is partly reflected in scales like Barron (1963) Fundamentalist Belief scale, can only be sustained by accepting the validity of the conservative view. Therefore, it should not be surprising that literal believers tend to score higher on measures of prejudice and lower on cognitive development and can be characterized as rigid and low in their ability to adapt. People occupying this quadrant accept the existence of the religious realm as well as religious doctrines, but they interpret them literally.

The lower left quadrant, Literal Disaffirmation, represents a position in which the individuals reject the existence of the religious realm. Moreover, the possibility that the religious language has a symbolic meaning is lost. Therefore, as in the upper left quadrant, religious language is understood in a literal way. The difference lies in the fact that the individuals who demonstrate Literal Disaffirmation reject what is written or said as a religious doctrine or dogma. If anything is made absolute, it is the scientific method and rational and formal principles of knowledge. According to Wulff $(1991,1997,1999)$, this position is partly reflected in the indiscriminately anti-religious orientation identified by Allport and Ross (1967) as well as in Barron (1963) Fundamentalist Disbelief scale. People occupying this quadrant tend to be less dogmatic and more intellectual than representatives of other religious types (see Wulff 1991, 1997, 1999).

The lower right quadrant, Reductive Interpretation, represents a position in which individuals reject the existence of the religious realm. However, they claim a privileged perspective on the hidden meaning of religion's myths and rituals and allow that religion can have symbolic functions. This quadrant is derived from the work of Ricoeur (1970), who proposed that, in modern hermeneutics, in order to clear away from religious symbols, the excrescence of idolatry and illusion, a Reductive Interpretation is necessary. Wulff (1991, 1997, 1999) draws on findings obtained with scales such as Batson (1976) Quest scale and Barron (1963) Enlightenment Disbelief scale to fill out a portrait of individuals in this quadrant. He concludes that these individuals are complex, socially sensitive and insightful, relatively unprejudiced, and original.

Finally, the upper right quadrant, Restorative Interpretation, represents a position in which the individuals affirm the existence of the religious realm but try to encompass and 
transcend all possible Reductive Interpretations in order to find the symbolic meaning of religious language. Again, this quadrant is derived from the work of Ricoeur (1970), who proposed that, in modern hermeneutics, in order to make it possible for the object of suspicion to be restored to an object of understanding and faith, a Restorative Interpretation is necessary. In this respect, Ricoeur introduced the concept of Second Naiveté. According to Wulff $(1991,1997,1999)$, to characterize individuals who occupy this position is quite difficult, for until recently, researchers have largely neglected this area in empirical research. Nevertheless, Fowler (1981) shows this posture in his fifth stage (conjunctive faith) of faith development. This stage is achieved at the moment of going beyond the defined attitude to religion, characteristic for a previous stage of the individual-reflective faith. This moment allows disillusionment to appear, which results from the awareness that life is more complicated than the clear differences and abstract notions of classical thinking propose. Research with scales designed to operationalize this stage might therefore cast light on this position (Duriez et al., 2000, 2005; Duriez and Hutsebaut 2001).

Inspired by Wulff (1991, 1997), Hutsebaut (1996) developed the Post-Critical Belief scale. This scale consisted originally of 24 items that captured the four approaches to religion determined by Wulff within a secularized Christian context. Hutsebaut (1996) carried out an initial analysis of the internal structure of the Post-Critical Belief scale in a mixed sample of adolescents, university students and adults. However, it offered only partial support for Hutsebaut's contention that the Post-Critical Belief scale was a valid measure of Wulff's concepts. Moreover, factor analysis followed by VARIMAX rotation pointed neither to two bipolar factors referring to the two bipolar dimensions discerned by Wulff nor to four unipolar factors referring to Wulff's four quadrants. Instead, three unipolar factors emerged. Items that referred to the acceptance of Christian beliefs had a positive loading on the first factor. This factor could easily be interpreted in terms of what Wulff called Literal Affirmation, and Hutsebaut (1996) labeled it as Orthodoxy. Next, items with a significant loading on the second factor referred either to the meaningfulness of the Christian religion or to its historical relativity. Hutsebaut (1996) described it as consistent with what Wulff called Restorative Interpretation and labeled it as Historical Relativism. Items aimed at measuring either what Wulff called Literal Disaffirmation or Reductive Interpretation had a positive loading on the third factor. Therefore, Hutsebaut determined that this factor measures Exclusion of Transcendence and labeled it External Critique (see Fig. 1). ${ }^{1}$ We adopted the terminology of our sources although important

\footnotetext{
1 In subsequent studies, Duriez et al. (2000) re-investigated the internal structure of the Post-Critical Belief scale using multidimensional scaling (MDS). A two-dimensional MDS representation of the relationships between the items of the PCBS could be interpreted by means of both a dimensional and a regional interpretation. The first dimension could be interpreted as Exclusion vs. Inclusion of Transcendence. The second dimension could be interpreted in terms of Literal vs. Symbolic. This dimensional interpretation was compatible with the regional interpretation. The Orthodoxy items were situated in the upper left quadrant, the External Critique items were situated in the lower left quadrant, and most Historical Relativism items were situated in the upper right quadrant. However, some of the Historical Relativism items were situated in the lower right quadrant. A close inspection of the items revealed a difference in content between the items in the upper right and the lower right quadrants. The items in the upper right quadrant clearly implied an adherence to Christian religion, while the items in the lower right quadrant merely focused on the historical relativity of Christian religion without implying an adherence to it. Hence, both the position and the content of the items in the lower right quadrant indicated that these items were not suited to measure Restorative Interpretation. Therefore, Duriez et al. (2000) decided to divide Historical Relativism into two parts. The upper right quadrant, implying Inclusion of Transcendence, was labeled Second Naiveté. The lower right quadrant, referring to a purely relativist stance, was labeled Relativism (cf. Fontaine et al. 2003; Duriez and Hutsebaut 2010).
} 
philosophical questions can and should be raised about the precise intent and ultimate appropriateness of these terms.

In subsequent studies, factor analysis confirmed the existence of these three factors (see Hutsebaut 1997; Desimpelaere et al. 1999; Duriez et al. 2000; Fontaine et al. 2003). Based on the empirical research, Hutsebaut et al. (Duriez et al. 2000) conclude that the PostCritical Belief scale is a promising scale for the measurement of religious attitudes in a secularized context, but the internal structure of the Post-Critical Belief scale does not fit Wulff's model very well. According to Wulff $(1991,1997)$, the domain of religion is characterized by two bipolar dimensions (Inclusion vs. Exclusion of Transcendence and Literal vs. Symbolic) that give rise to four approaches to religion. Instead of two bipolar dimensions, three unipolar factors are identified in the PCBS scale. We chose to go with Hutsebaut's Post-Critical Belief scale.

We measured the correlation between the three attitudes toward religion and Cattell's factors of anxiety. Bearing in mind that Hutsebaut's model is relatively new, and not yet adequately tested, and that formulating hypotheses is a rather tentative business, we, nevertheless, tried to make at least some predictions with regard to the relationship of postcritical beliefs with anxiety. We propose the hypothesis that a literal understanding of religion (Orthodoxy and External Critique) should correlate positively with anxiety and symbolic interpretation of religion (Historical Relativism) should correlate negatively with anxiety. Hence, we expect that individuals who are situated in the Historical Relativism group score lower on anxiety than those who are situated in the two other groups (Orthodoxy and External Critique). Literal and symbolic interpretations are different but equally legitimate ways to express intended meaning. They pertain to educational level and differentiations of consciousness, e.g. the ability to switch to thinking in different ways and to interrelate them easily (i.e. Lonergan 1972).

As neither existing research nor theoretical assumptions allowed for formulating hypotheses, including differences in gender, we treat this part of our study as exploratory in nature.

\section{Method}

Participants

We tested 83 individuals (46 women and 37 men) aged 25-45 $(M=31.82$; SD $=7.21)$. There are no statistically significant differences in terms of age between women and men. In the tested sample, individuals with a higher $(N=50)$ and secondary $(N=28)$ education constitute the majority. The vast majority of subjects come from an urban environment $(N=70)$.

\section{Measures}

We applied two psychological tests: Hutsebaut's Post-Critical Belief scale and Cattell's IPAT Anxiety scale.

We used the Post-Critical Belief scale by D. Hutsebaut to measure attitude toward religion. This scale consists of 24 items that are to measure Orthodoxy, External Critique and Historical Relativism (Hutsebaut 1996, 1997, 2000; Duriez et al. 2000).

A high score on the scale of Orthodoxy means that the person claims that there is only one true answer to religious questions and this answer is accepted by religious authorities. 
A high score on the scale of External Critique suggests that the person displays a tendency toward disbelief, yet religion plays a role in his/her life, although usually in a negative or ambivalent way and the person questions the meaning of religious beliefs fundamentally. Historical Relativism indicates that the person accepts the existence of God but less than orthodox individuals do. For this person, thought and talk about faith are relative; that is, different interpretations of religion and the changeability of its meaning in both a particular context and a historical perspective are acceptable.

We measured these three dimensions by means of eight items each. Answers were given on a 7-point Likert scale. The minimum possible score is eight and the maximum, 58 points. J. Śliwak translated PCBS into Polish.

The IPAT Anxiety scale (Krug et al. 1976) was used to measure free-floating anxiety, which is not the anxiety or fear triggered by a particular stimulus. This scale consists of Cattell's 16 Personality Factors (16 PF) Questionnaire (1957). Cattell chose all items related to anxiety reactions from the $16 \mathrm{PF}$. As a result of a factor analysis, he separated 5 individual factors that constitute a Total Anxiety factor: emotional instability (C), suspiciousness (L), guilt proneness $(\mathrm{O})$, lack of integration $(\mathrm{Q} 3)$ and tension $(\mathrm{Q} 4)$. Using these factors, he examined 3,000 individuals, calculated the discriminatory power of the items and left 40 items with the highest diagnostic value. Half of the items are related to the covert anxiety indicators that do not refer to anxiety. These are, for instance, sudden changes of interests, somatic disorders (dyspepsia, cardiac arrhythmias) and feelings of jealousy. The other half is related to the overt anxiety indicators, e.g., perceiving oneself as a nervous person, experiencing tension and agitation and experiencing uneasy sleep (Cattell and Schuerger 2003).

Krug et al. (1976) reported the total score test-retest reliability of the IPAT scale at 4 weeks as .82. Internal consistency reliability of the Total Anxiety score was between .78 and .92. K. Hirszel translated the IPAT Anxiety scale into Polish, and Z. Płużek prepared a psychological interpretation. High validity and reliability characterize the test (Siek 1983).

\section{Results}

We calculated Spearman's rho coefficients among the Post-Critical Belief scale and Cattell's factors of anxiety for the general sample. We calculated these coefficients also for the subgroups of women and men.

Orthodoxy correlated with two anxiety factors, positively (rho $=.240$ ) with guilt proneness $(\mathrm{O})$ and negatively (rho $=-.213$ ) with suspiciousness $(\mathrm{L})$, in the general sample (Table 1). There were no statistically significant differences in the correlation between Orthodoxy and anxiety in the subgroups of women and men.

A different view concerns correlations between anxiety and Historical Relativism (Table 2). In the general sample, there were no statistically significant correlations between the analyzed variables. However, extremely different correlations appear in the subgroups of women and men. Among women, Historical Relativism correlated negatively with lack of integration $(\mathrm{Q} 3$; rho $=-.362)$ and suspiciousness $(\mathrm{L}$; rho $=-.430)$, whereas among men, it correlated positively with emotional instability $(\mathrm{C}$; rho $=.324)$, tension $(\mathrm{Q} 4$; rho $=.325)$ and overt anxiety $($ rho $=.357)$. In addition, in both the subgroups, Historical Relativism correlated with general anxiety and with covert anxiety negatively among women (rho $=-.295$, rho $=-.314$, respectively) and positively among men (rho $=.357$, rho $=.376$, respectively). 
Table 1 Correlations (rho-Spearman) of Orthodoxy with anxiety in a general sample and among women $(N=46)$ and men $(N=37)$

\begin{tabular}{lccc}
\hline Anxiety scale (Subscales) & Orthodoxy & \\
\cline { 2 - 4 } & General sample $(N=83)$ & Women $(N=46)$ & Men $(N=37)$ \\
\hline General anxiety & 0.098 & -0.002 & 0.014 \\
Q3 & -0.065 & -0.142 & -0.019 \\
C & -0.095 & -0.006 & -0.197 \\
L & $-0.213^{*}$ & -0.175 & -0.277 \\
O & $0.240^{*}$ & 0.124 & 0.158 \\
Q4 & 0.140 & 0.025 & 0.170 \\
Overt anxiety & 0.176 & 0.094 & 0.110 \\
Covert anxiety & -0.010 & -0.083 & -0.059 \\
\hline
\end{tabular}

$* P<0.05$

Table 2 Correlations (rho-Spearman) of Historical Relativism with anxiety in a general sample and among women $(N=46)$ and men $(N=37)$

\begin{tabular}{llll}
\hline Anxiety scale (Subscales) & \multicolumn{3}{l}{ Historical Relativism } \\
\cline { 2 - 4 } & General sample $(N=83)$ & Women $(N=46)$ & Men $(N=37)$ \\
\hline General anxiety & 0.037 & $-0.295^{*}$ & $0.423^{* *}$ \\
Q3 & -0.094 & $-0.362^{*}$ & 0.271 \\
C & 0.078 & -0.084 & $0.324^{*}$ \\
L & -0.101 & $-0.430^{* *}$ & 0.286 \\
O & 0.052 & -0.094 & 0.217 \\
Q4 & 0.104 & -0.120 & $0.352^{*}$ \\
Overt anxiety & 0.091 & -0.161 & $0.357^{*}$ \\
Covert anxiety & -0.013 & $-0.314^{*}$ & $0.376^{*}$ \\
\hline
\end{tabular}

$* P<0.05 ; * * P<0.01$

External Critique correlated positively (rho $=.376$ ) only with suspiciousness (L) among men (Table 3).

\section{Discussion}

This study examined relations among the Post-Critical Belief scale and Cattell's factors of trait anxiety. We concentrated on the strength and direction of particular correlations in the general group. Furthermore, we analyzed their specificity in sex-differentiated subgroups.

We found statistically significant correlations between the Post-Critical Belief scale and anxiety. In the general sample, we observed correlations between Orthodoxy and two factors of anxiety: negative regarding suspiciousness (L) and positive regarding guilt proneness $(\mathrm{O})$. We speculate that people high in Orthodoxy find safety in religion, but anxiety accompanies their literal understanding of religion. They experience the feeling of guilt (Baker and Gorsuch 1982), in particular when they cannot satisfy normative religious demands. Duriez and Hutsebaut (2001) found similar tendencies. Researchers noted that 
Table 3 Correlations (rho-Spearman) of External Critique with anxiety in a general sample and among women $(N=46)$ and men $(N=37)$

\begin{tabular}{lccl}
\hline Anxiety scale (Subscales) & \multicolumn{2}{l}{ External Critique } \\
\cline { 2 - 4 } & General sample $(N=83)$ & Women $(N=46)$ & Men $(N=37)$ \\
\hline General anxiety & 0.060 & -0.057 & 0.236 \\
Q3 & 0.066 & 0.006 & 0.220 \\
C & 0.107 & -0.027 & 0.246 \\
L & 0.170 & -0.012 & $0.376^{*}$ \\
O & -0.077 & -0.162 & 0.011 \\
Q4 & 0.014 & -0.037 & 0.065 \\
Overt anxiety & 0.058 & -0.110 & 0.226 \\
Covert anxiety & -0.052 & -0.035 & 0.151 \\
\hline
\end{tabular}

$* P<0.05 ; P<0.01$

people high on Orthodoxy tend to associate both positive and negative emotions with religion. According to Duriez and Hutsebaut (2001), inclusion of transcendence is related to associating religion with positive feelings, whereas approaching religion in a literal way is related to associating religion with negative feelings. These results seem to confirm studies conducted by other researchers. Zarzycka (2007) and Śliwak (2005) found positive correlations between Orthodoxy and the centrality and intensity of religiosity, and Hutsebaut (1996) found positive correlations between Orthodoxy and guilt proneness. Therefore, we suppose that Orthodoxy is a source of ambivalent emotional experiences in which trust in God is combined with elements of frustration, blame and fear.

We observed no significant correlations between External Critique and anxiety neither in the general sample nor in the subgroup of women. Among men, however, External Critique correlated positively with suspiciousness (L). This outcome supports Wulff's speculations that people high on External Critique are distrustful and suspicious toward religion and that, if they treat anything as absolute, it should be the scientific method and rational principles of knowledge. Hence, our study provides empirical support for a relationship between suspiciousness (L) and External Critique. Other studies also confirmed the results. For instance, External Critique correlated negatively with religious experience and worship (Zarzycka 2007). Hutsebaut (1996) found that this style correlated positively with the revolt against God. Duriez and Hutsebaut (2001) observed positive correlations between External Critique and aggression and depression, and Exline et al. (1999) found positive relationships between atheism and anger toward God. Nevertheless, Hutsebaut (1996), Duriez and Hutsebaut (2001) and Zarzycka (2007) derived their data from studies carried out on groups that were not sex-differentiated. Authors conducted no analyses in the subgroups of men and women. We cannot explain why the positive correlation between External Critique and suspiciousness (L) is present only among men. It seems that further research on religiosity with particular attention to gender is needed.

With regard to Historical Relativism, which corresponds to Restorative Interpretation, we found a stronger correlation with anxiety but, interestingly enough, not in the general sample but in the subgroups of women and men. In both women and men, Historical Relativism correlated with general anxiety and covert anxiety, but correlations are negative among women and positive among men. In the group of women, Historical Relativism correlated negatively with the lack of integration (Q3) and suspiciousness (L) and in the 
group of men, positively with emotional instability (C), tension (Q4) and overt anxiety. These results suggest that anxiety is related to Historical Relativism differently among men and women. Women high in Historical Relativism have low anxiety, whereas men high in Historical Relativism have high anxiety. These issues are difficult, not easily dispatched, disputed, and our opinion expressed is supposition and speculation, a struggling attempt to make sense of the data.

Several authors have posited that observed differences between men and women in religious participation are a function of socialization by which women are socialized to be focused relationally and men are taught to value achievement and power (Simpson et al. 2008; Hall 1997; Mahalik and Lagan 2001; Reich 1997; Stokes 1990; Thompson 1991).

Other discussions regarding sex and gender differences in religiousness have focused on the role of connected versus separate knowing (cf. Simpson et al. 2008). According to Belenky et al. (1986), separated knowers take an impersonal stance since they rigorously exclude personal beliefs and feelings, while connected knowers emphasize feelings and use empathy and listening to try to understand others. Ozorak (1996) found that "women conceptualize religion in terms of relationship rather than individuation" (p. 23) and noted that women tended to prefer a relational interaction with God as opposed to a more distant participation characterized by individuation (e.g., knowing through reason, viewing God as a distant judge, etc.).

Other discussions refer to the concept of Kohlberg's $(1973,1981)$ moral development and its evaluation carried out by Gilligan $(1982,1988)$. According to Gilligan, there is a relationship between the way people define themselves and moral reasoning. In experiencing his self, a man defines himself by separating himself from the rest of the world and by stressing his special position in it, and this position is evaluated by referring to objective rules. A woman determines herself in relation to her relationship to the world and other people, and it is evaluated on the basis of particular acts of care and concern. This dissimilar experiencing of self is a source of different conflicts and development problems. On the one hand, men struggle with feelings and emotions when objective rules change, and the logic of justice loses its obligatory power. Women, on the other hand, base their reasoning on the dependency on situational context and adapt their functioning to the extent to which a particular situation is detailed and specific (Gilligan 1982).

Dichotomy, separate and connected knowing seems too simple. It would seem to apply rather easily to styles of interpersonal communication and engagement, empathy and listening to try and understand others, but not to faith and religion. Yet, women think also critically, scientifically, objectively and men rely on interpersonal connections and affective sensibility to deal with pertinent issues. This categorization simply seems stereotypical. Also, conceptualization in terms of relationship and individuation seems not to explain the differences between men and women. Individuals enter relationship, and the more individuated the individuals are, the deeper the relationships are likely to be. All approaches to God are some way relational, i.e. between two objects and individuation make rather for deeper relationship, even with God. The observed associations between Historical Relativism and anxiety seem to be too complex to be passed over with merely suggestive labels. We just do not know what it exactly means, and it raises questions for further explicitly focused research. And this all the more as Historical Relativism is the least valid operationalization of Wulff's $(1991,1999)$ theoretical construct. In his first PCBS scale, Hutsebaut (1996) failed to achieve two independent factors that measure symbolic attitudes toward religion (Restorative Interpretation and Reductive Interpretation), aimed at corresponding to Wulff's model. Instead, he obtained one factor as a measure of symbolic interpretation of religion, which did not allow him to differentiate 
people in terms of Inclusion vs. Exclusion of Transcendence. It was only the second adaptation phase that the authors (Duriez et al. 2000) managed to divide Historical Relativism into two factors corresponding to Wulff's model. In our research, we understood Historical Relativism as a measure of symbolic interpretation of religion. However, this interpretation should be treated with due caution, and it requires verification by means of a four-factor PCBS scale.

\section{Conclusions}

Several authors have searched for relations between religiosity and anxiety, in particular in the context of analysis of the function of religiosity in the personality (Shreve-Neiger and Edelstein 2004). A review of the empirical research on the relationships between religiosity and psychic health (Gartner et al. 1991) as well as between religiosity and anxiety (ShreveNeiger and Edelstein 2004) reveals an inconsistency of the research results. Some of the researchers suggest that there is no correlation between religiosity and anxiety (Fehr and Heintzelman 1977; Frenz and Carey 1989; Francis and Jackson 2003; Huntley and Peeters 2005). Others show that there are significant correlations between these variables. These researchers also call for more research and analyses and point to the need for defining both variables, not in the categories of a single construct, but with regard to particular dimensions of religiosity and to typological and structural elements of anxiety (Baker and Gorsuch 1982; Harris et al. 2002; Shreve-Neiger and Edelstein 2004). This study supports this attention to a multidimensional perspective of both religiosity and anxiety. Whereas Orthodoxy was related to a stronger guilt proneness $(\mathrm{O})$ and lower suspiciousness $(\mathrm{L})$ in the general sample, External Critique was related only to stronger suspiciousness (L) among men. Historical Relativism correlated negatively with anxiety in the subgroup of women but positively in the subgroup of men. Therefore, it seems that further exploration of the "established" relationship between religiousness and gender might be useful.

Open Access This article is distributed under the terms of the Creative Commons Attribution Noncommercial License which permits any noncommercial use, distribution, and reproduction in any medium, provided the original author(s) and source are credited.

\section{References}

Allport, G. W., \& Ross, J. M. (1967). Personal religious orientation and prejudice. Journal of Personality and Social Psychology, 5, 432-443.

Baker, M., \& Gorsuch, R. (1982). Trait anxiety and intrinsic-extrinsic religiousness. Journal for the Scientific Study of Religion, 21, 119-122.

Barron, F. (1963). Creativity and psychological health: Origins of personal vitality and creative freedom. Princeton, NJ: Van Nostrand.

Batson, C. D. (1976). Latent aspects of "From Jerusalem to Jericho". In M. P. Golden (Ed.), The research experience. Itasca, Ill: F.E. Peacock.

Belenky, M. F., Clinchy, B. M., Goldberger, N. R., \& Tarule, J. M. (1986). Women's ways of knowing: The development of self, voice, and mind. New York: Basic Book.

Bergin, A. E., Masters, K. S., \& Richards, P. S. (1987). Religiousness and mental health re-considered: A study an intrinsically religious sample. Journal of Counseling Psychology, 34, 197-204.

Cattell, R. B. (1957). Personality and motivation structure and measurement. New York: World Book.

Cattell, H. E. P., \& Schuerger, J. M. (2003). Essentials of $16 P F^{\circledR}$ assessment. London: Wiley.

Davis, T. L., Kerr, B. A., \& Kurpius, S. E. R. (2003). Meaning, purpose, and religiosity in at-risk youth: The relationship between anxiety and spirituality. Journal of Psychology \& Theology, 31(4), 356-365. 
Desimpelaere, P., Sulas, F., Duriez, B., \& Hutsebaut, D. (1999). Psycho-epistemological styles and religious beliefs. The International Journal for the Psychology of Religion, 9(2), 125-137.

Duriez, B., Fontaine, J. R. J., \& Hutsebaut, D. (2000). A further elaboration of the Post-Critical Belief scale: Evidence for the existence of four different approaches to religion in Flanders-Belgium. Psychologica Belgica, 40, 153-181.

Duriez, B., \& Hutsebaut, D. (2001). The interplay between how people approach religion and the emotions they associate with religion: an exploratory study in Flanders (Belgium). Journal of Empirical Theology, 14, 75-84.

Duriez, B., \& Hutsebaut, D. (2010). A slow and easy introduction to the Post-Critical Belief Scale. Internal structure and external relationships. In: D. M. Wulff (Ed.), Handbook of the psychology of religion. Oxford University Press (in press).

Duriez, B., Soenens, B., \& Hutsebaut, D. (2005). Introducing the shortened Post-Critical Belief Scale. Personality and Individual Differences, 38(4), 851-857.

Exline, J. J., Yali, A. M., \& Lobel, M. (1999). When God disappoints: Difficulty forgiving God and its role in negative emotion. Journal of Health Psychology, 4, 365-379.

Fehr, L. A., \& Heintzelman, M. E. (1977). Personality and attitude correlates of religiosity: A source of controversy. The Journal of Psychology, 95, 63-66.

Fontaine, J. R. J., Duriez, B., Luyten, P., \& Hutsebaut, D. (2003). The internal structure of the Post-Critical Belief scale. Personality and Individual Differences, 35(3), 501-518.

Fowler, J. W. (1981). Stages of faith: The psychology of human development and the quest for meaning. San Francisco: Harper \& Row.

Francis, L. J., \& Jackson, C. J. (2003). Eysenck's dimensional model of personality and religion: are religious people more neurotic? Mental Health, Religion \& Culture, 6(1), 87-100.

Frenz, A. W., \& Carey, M. P. (1989). Relationship between religiousness and trait anxiety: Factor or artifact? Psychological Reports, 65, 827-834.

Gartner, J., Larson, D. B., \& Allen, G. D. (1991). Religious commitment and mental health: A review of the empirical literature. Journal of Psychology and Theology, 19(1), 6-25.

Gilligan, C. (1982). In a different voice: Psychological theory and women's development. Boston: Harvard University Press.

Gilligan, C. (1988). Mapping the moral domain: A contribution of women's thinking to psychological theory and education. Boston: Harvard University Press.

Gupta, A. (1983). Mental health and religion. Asian Journal of Psychology and Education, 11, 8-13.

Hall, T. A. (1997). Gender differences: Implications for spiritual formation and community life. Journal of Psychology and Christianity, 16, 212-232.

Harris, J. I., Schoneman, S. W., \& Carrera, S. R. (2002). Approaches to religiosity related to anxiety among college students. Mental Health, Religion \& Culture, 5(3), 253-265.

Huntley, C., \& Peeters, T. (2005). Paranormal beliefs, religious beliefs and personality correlates. Paper presented in April 2005 at Manchester Metropolitan University.

Hutsebaut, D. (1980). Belief as lived relations. Psychologica Belgica, 20(1), 33-47.

Hutsebaut, D. (1996). Post-critical belief. A new approach to the religious attitude problem. Journal of Empirical Theology, 9(2), 48-66.

Hutsebaut, D. (1997). Identity statuses, ego-integration, God representation and religious cognitive styles. Journal of Empirical Theology, 10(1), 39-54.

Hutsebaut, D. (2000). Post-Critical belief scales. Journal of Empirical Theology, 13(2), 19-28.

Kohlberg, L. (1973). The claim to moral adequacy of a highest stage of moral judgment. Journal of Philosophy, 70, 630-646.

Kohlberg, L. (1981). Essays on moral development. Vol I: The philosophy of moral development. New York: Harper \& Row.

Krug, S. E., Scheier, I. H., \& Cattell, R. B. (1976). Handbook for the IPAT Anxiety Scale. Champaign, IL: Institute for Personality and Ability Testing.

Loewenthal, K. (2006). Religion, culture and mental health. Cambridge: Cambridge University Press.

Lonergan, B. J. F. (1972). Method in theology. New York: Herder \& Herder.

Mahalik, J. R., \& Lagan, H. D. (2001). Examining masculine gender role conflia and stress in relation to religious orientation and spiritual well-being. Psychology of Men \& Masculinity, 2, 24-33.

Maltby, J. (1998). Church attendance and anxiety change. The Journal of Social Psychology, 138(4), 537538.

Ozorak, E. W. (1996). The power, but not the glory: How women empower themselves through religion. Journal for the Scientific Study of Religion, 35(1), 17-29.

Pfeifer, S., \& Waelty, U. (1999). Anxiety, depression, and religiosity-a controlled clinical study. Mental Health, Religion \& Culture, 2(1), 35-45. 
Prężyna, W. (1969). Postawa religijna a cechy osobowości analizowanej w świetle danych 16- czynnikowego kwestionariusza R. B. Cattella [Religious attitude and Cattell's personality traits]. Roczniki Filozoficzne, 17, 4.

Rasmussen, C. H., \& Johnson, M. E. (1994). Spirituality and religiosity: Relative relationships to death anxiety. Omega: The Journal of Death and Dying, 29, 313-318.

Reich, K. H. (1997). Do we need a theory of religious development for women? The International Journal for the Psychology of Religion, 7, 67-86.

Ricoeur, P. (1970). Freud and philosophy: An essay on interpretation (D. Savage, Original French edition 1965, Trans.). New Haven, CT: Yale University Press.

Roff, L. L., Butkeviciene, R., \& Klemmack, D. L. (2002). Death anxiety and religiosity among Lithuanian health and social service professionals. Death Studies, 26, 731-742.

Shreve-Neiger, A. K., \& Edelstein, B. A. (2004). Religion and anxiety: A critical review of the literature. Clinical Psychology Review, 24, 379-397.

Siek, S. (1983). Wybrane metody badania osobowości. [Selected methods of investigating personality]. Warszawa: Akademia Teologii Katolickiej.

Simpson, D. B., Cloud, D. S., \& Newman, J. L. (2008). Sex and gender differences in religiousness and spirituality. Journal of Psychology and Theology, 36(1), 42-52.

Śliwak, J. (2005). Religijne style poznawcze a postawy wobec śmierci [Religious cognitive styles and attitudes toward death]. In J. Makselon (Ed.), Człowiek wobec smierci. Aspekty psychologicznopastoralne [Man's concern with death. Psychological-pastoral aspects.] (pp. 317-336). Kraków: Wydawnictwo Naukowe PAT.

Śliwak, J. (2006). Niepokój a religijność. [Anxiety and religiosity]. Roczniki Psychologiczne, 9(1), 53-81.

Stokes, K. (1990). Faith development in the adult life cycle. Journal of Religious Gerontology, 7, 167-184.

Sturgeon, R. S., \& Hamley, R. W. (1979). Religiosity and anxiety. The Journal of Social Psychology, 108, $137-138$.

Thompson, E. H. (1991). Beneath the status characteristics: Gender variations in religiousness. Journal for the Scientific Study of Religion, 30, 381-394.

Westman, A. S., \& Brackney, B. E. (1990). Relationships between indices of neuroticism, attitudes toward and concepts of death, and religiosity. Psychological Reports, 66, 1039-1043.

Wilson, W., \& Miller, H. L. (1968). Fear, anxiety and religiousness. Journal for Scientific Study of Religion, 7, 111 .

Wulff, D. M. (1991). Psychology of religion: classic and contemporary views. New York: Wiley.

Wulff, D. M. (1997). Psychology of religion. Classic and contemporary views. New York: Wiley.

Wulff, D. M. (1999). Psychologia religii. Klasyczna i wspotczesna [Psychology of religion: Classic and contemporary views]. Warszawa: Wydawnictwo Szkolne i Pedagogiczne.

Zarzycka, B. (2007). Skala Centralności Religijności S. Hubera. [The Polish version of S. Huber's centrality of religiosity scale]. Roczniki Psychologiczne, 10(1), 133-157. 